\title{
Recommendations and solutions to remove some barriers to the deployment of smart grid in Morocco
}

\author{
Rachid Habachi, Achraf Touil, Abdellah Boulal, Abdelkabir Charkaoui, \\ Abdelwahed Echchatbi \\ Laboratory of Mechanical Engineering, Hassan 1st University, Morocco
}

\begin{tabular}{|c|c|}
\hline Article Info & ABSTRACT \\
\hline Article history: & In this paper, we identify the current state and prospects of smart grids in \\
\hline Received Jan 12, 2019 & $\begin{array}{l}\text { Morocco. We begin by describing the current state of the Moroccan network, } \\
\text { then we study the obstacles to the development of smart grids in Morocco }\end{array}$ \\
\hline Revised Mar 3, 2019 & and internationally. We conclude with recommendations and solutions to \\
\hline Accepted Mar 23, 2019 & $\begin{array}{l}\text { remove some barriers to the deployment of intelligent electrical networks in } \\
\text { Morocco. }\end{array}$ \\
\hline
\end{tabular}

Keywords:

Adoption barriers

Moroccan network

Renewable energies,

Smart grid system,

\section{Corresponding Author:}

Rachid Habachi, Laboratory of Mechanical Engineering,

Hassan 1st University,

PO Box 577, Settat, Morocco.

Email: habachirachid@gmail.com

\section{INTRODUCTION}

Morocco is a country where energy policy is paramount to the example of emerging countries. The evolution of electricity demand is due to several factors. The evolution of the population increases domestic consumption, the modernization of lifestyles and rural electrification also accentuate the dependence of the citizens in their daily life of the electric network.

Moreover, the country agrees and knows the advantage of high demand at the industrial level. The development plans and support industries have been initiated and have generated foreign and local investments while in many heavy industry with high energy consumption.

Awareness of these issues has led to a strategic investment and development laws that authorize and support the diversity of the electric power system in Morocco.

Projects launched at national level for several years focused on renewable energies confirm an energy transition. They make it possible to reduce the dependence of the fossil fuel sector subject to enormous fluctuations. [1].

The electricity generated in Morocco is mainly produced by ONEE and three other independent power producers [2]: the energy company JorfLasfar (JLEC $2020 \mathrm{MW}$ ), the Abdelkhalek Torres wind power station (THEOLIA $50 \mathrm{MW}$ ) and the basic electrical power (EET $380 \mathrm{MW}$ ).

Morocco has adopted its National Energy Strategy (NES) with corresponding targets for 2020 in 2009 and renewed it in Paris at the end of 2015 with targets until 2030. Addressing the three main challenges of modern energy policy, security, affordability and sustainability. The NES focuses on four main objectives: to secure energy supply, to control energy demand, to generalize access to energy for all segments of the population at affordable and competitive prices and to preserve the environment [3]. 
Smart grids are a set of technologies, concepts and approaches, allowing the integration the generation, transmission, distribution and use into one internet by full use of advanced sensor measurement technology, communications technology, information technology, computer technology, control technology, new energy technologies [4]. However, Smart Grid uses digital technology to control grid and choosing the best mode of power distribution to reduce energy consumption, reduce costs, increase reliability and also increase transparency in the network. Therefore, the system intelligent will have a significant impact in the fields of finance and economics of the power industry [5].

The increasing development of computer systems and information networks, power grids should change extensively too. Nowadays, substantial movement has begun to implement the Smart Grid industry around the world. Since with the creation of smart electricity grids, it is possible to access the internal network from the external spaces, it is also necessary to protect information and data against unauthorized access. Therefore, a firewall should be used for information security. The firewall based on existing security regulations, decides which data is incoming to the network or going out of the network. Considering the discussions of passive defense topics at the national level and also the high importance of information security in Smart Grids,. Although the firewall has a major role in establishing security, and its installation and appropriate configuration can only be one of the primary activities in this field, we should also take advantage of other security mechanisms to enhance the security of the Smart Grid[6].

The paper is organized as follows. Section 2 presents the current state of the moroccan network Next, section 3 discusses the obstacles to the development and implementation of smart grids in morocco. Finally, Section 4 presents conclusions.

\section{CURRENT STATE OF THE MOROCCAN NETWORK}

\subsection{Characteristics of the current electricity grid}

Morocco has a network comprising: $3000 \mathrm{~km}$ of $400 \mathrm{KV}$ lines, nearly $9680 \mathrm{~km}$ of $225 \mathrm{KV}$ lines, 147 $\mathrm{km}$ of $150 \mathrm{KV}$ lines and approximately $12000 \mathrm{~km}$ of $60 \mathrm{KV}$ lines [7]. ONEE has launched a program to strengthen the transmission networks and their electricity supply with $980 \mathrm{~km}$ of $400 \mathrm{KV}, 1292 \mathrm{~km}$ of $225 \mathrm{KV}$ and $382 \mathrm{~km}$ of $60 \mathrm{KV}$.

This network was built fifty years ago and is a mix of old and new technology. The majority of network components are obsolete and continue to age due to constraints such as extreme temperatures, vibrations, water infiltration and damage from civil works. This problem makes the distribution system vulnerable and dangerous for Moroccan industry and the environment.

On the other hand, electricity demand is currently growing at 7\% per year. On July 28, 2015, during the period of extreme heat in all regions of Morocco, the demand for electricity peaked at 5860 MW, reaching 3.4\% compared to the peak recorded in 2014, mainly due to the use of electricity. air conditioning and agricultural pumping. Thus, the growth and the load of the current electrical system require a strong need for improvement of the Moroccan electricity network.

The architecture of the Moroccan electricity distribution network is illustrated in Figure.1 [8]. The primary function of network systems, is designed to support large production facilities serving remote consumers, via two main systems that connect to the transport and distribution levels. In fact, the transmission system transports electricity from power stations on high voltage transmission lines $(>60 \mathrm{kV})$ to distribution substations, where the voltage level is converted to $\mathrm{HV}$ and distributed to networks via transmission lines in general. Close to customers, the voltage supply is for domestic use, this system is essentially a unidirectional power flow.

This grid was built fifty years ago and is a mix of old and new technology. The majority of network components are obsolete and continue to age due to stresses such as temperature extremes, vibration, water infiltration and damage caused by civil works. This problem makes the distribution system vulnerable and dangerous for the Moroccan industry and for the environment.

On the other hand, electricity demand is currently growing at a fast pace (7\% per year). On July 28, 2015, electricity demand in Morocco reached a peak of $5860 \mathrm{MW}$, reaching 3.4\% compared to the maximum recorded in 2014, mainly due to the use of air conditioning and agricultural pumping for the purpose of 'irrigation. Period of extreme heat that all regions of Morocco [9]. Thus, the growth and the load of the current electrical system require an urgent need to upgrade the electrical network.

The architecture of the Moroccan electricity distribution network illustrated in (Figure 1) is adapted to the architecture explained in [10].

The primary function of network systems is designed to support large production facilities serving remote consumers via two primary systems that connect to transmission and distribution levels. For example, the transmission system transports power from power stations on high-voltage transmission lines $(>60 \mathrm{kV})$ to distribution substations, which converts the voltage level to medium voltage and distributes it to networks

Recommendations and solutions to remove some barriers to the deployment of smart ... (Rachid Habachi) 
via transport networks in general. Close to customers. Power supply at the voltage required for home use; This system is essentially a unidirectional power flow.

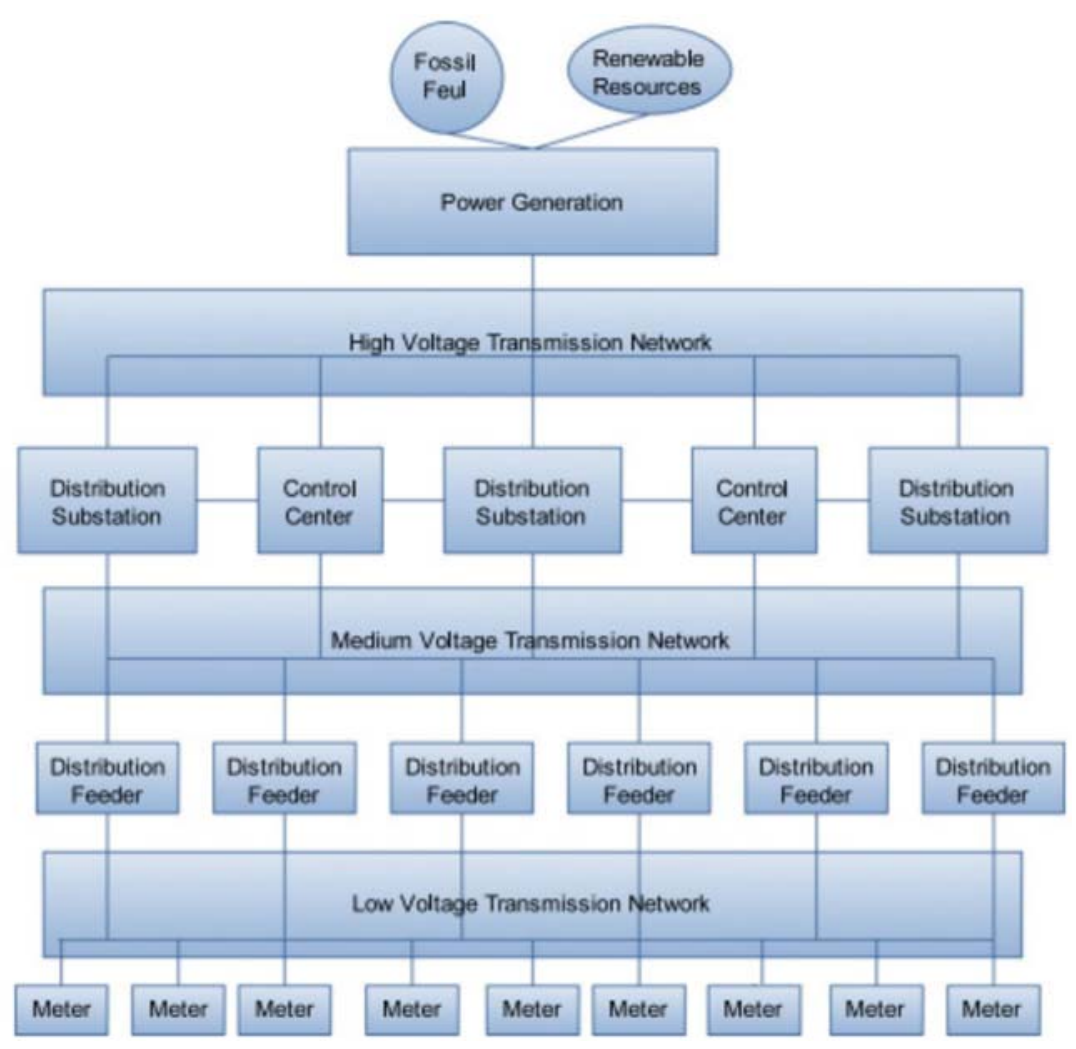

Figure 1. The architecture of the electricity distribution network [8]

\subsection{Regulatory frameworks for the electricity sector}

Some years after its independence, Morocco took the decision to take on its own account a strategic sector of the economy such as ecurity. Thus he oversaw the organization of the transmission and distribution of electrical energy. It has, however, promoted a regulatory framework without which the management of this sector would be impossible. Through a legal arsenal in the form of laws, dahirs and official decrees, stakeholders in the sector have been defined by specifying their responsibilities, their fields of intervention and their responsibilities.

Indeed, by Dahir 1-63-226 of August 5, 1963, the National Office of Electricity (ONE) was created in January of the same year under the administrative supervision of the Minister of Public Works. According to the evolution of the sector over the years this dahir has been completed and modified by the decrees and dahirs of the years 1994, 2002, 2006, 2008, 2015, 2016. Except the restrictions of article 3 of the same dahir and renewable energies, managed by law 13-09, the ONE is responsible for the public service, the production of the transmission and the distribution of electrical energy [11].

Law $\mathrm{N}^{\circ} 48-15$, appeared on July 7, 2016, gave birth to a national authority of regulation of the sector of electricity bearing the name ANRE. This law also prescribes the missions of the manager of the national electricity transmission network and the distribution network operators. In addition to the tasks assigned to it by Law No. 13-09, the National Transmission System Operator carries out its duties in accordance with the provisions of this law and the clauses of its specifications approved by regulation. The manager of the national transmission grid is responsible for the operation, maintenance and development of the national transmission grid and, where applicable, for its interconnections with the electricity transmission networks of foreign countries. Similarly, he is responsible for [12]:

- Manage the flow of electrical energy on the national transmission grid; 
- To ensure a real-time balance between production capacity and consumption needs, by making use of available production capacities and taking into account exchanges with other interconnected networks;

- Ensure the safety of the national transmission system, its stability, reliability and efficiency.

Law No. 13-09 on renewable energies, promulgated by Dahir No. 1-10-16 of 26 Safar 1431 (February 11, 2010) published in the Official Bulletin No. 5822 of the 1st Rabii II 1431 (March 18, 2010) ended the monopoly of the production of electrical energy by the ONE at least for renewable energies. Thus, by this law the production of electric energy from renewable energy sources is provided by the ONE, concurrently with legal entities of public or private law or natural persons, in accordance with the provisions of this law and texts. Taken for its application.

\subsection{Interconnection with neighboring countries}

To ensure continuity of electricity supply, the Moroccan network is reinforced by interconnections with neighboring countries, thereby guaranteeing the reliability of supply, security, and the mutual stability of all networks. These interconnections can also increase the maximum capacity of the electrical energy. It also develops the technical and economic exploitation of the energy of the production and transport systems of the interconnected countries. Currently, Morocco has two interconnections with Spain and Algeria. These interconnections will be reinforced by doubling the capacity of the new lines and the other interconnections with Portugal and Mauritania are under consideration. The strengthening and development of energy interconnections with neighboring countries is illustrated in Figure 2 [13].

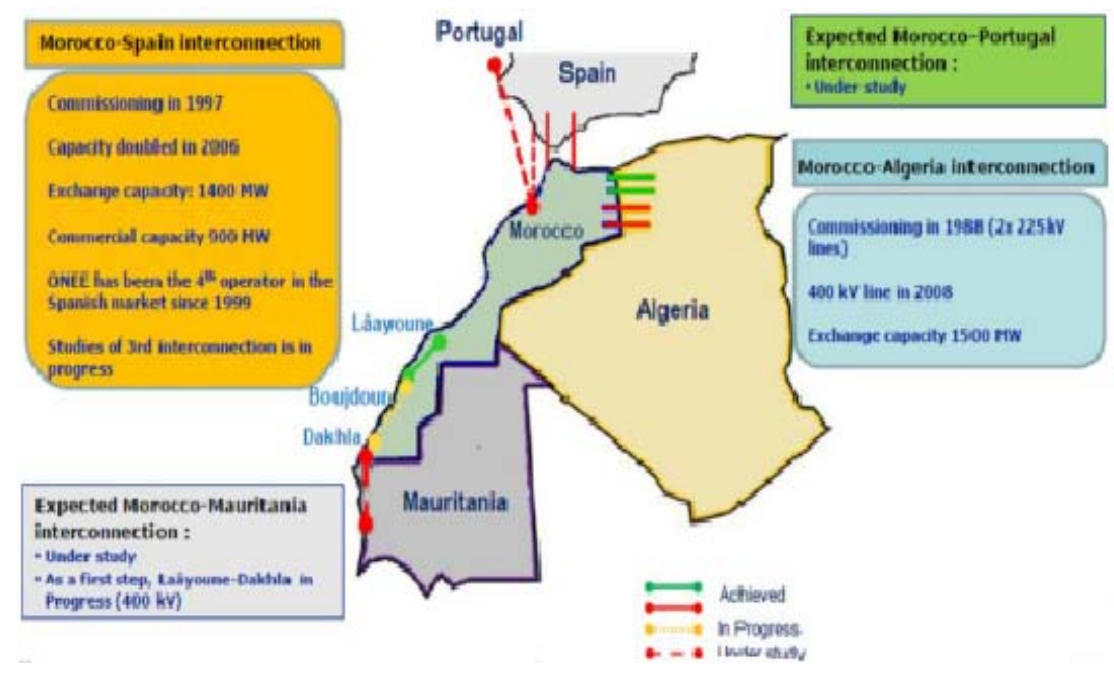

Figure 2. Strengthening and development of the energy interconnection with neighboring countries [13].

\subsubsection{Interconnection between Morocco and Spain}

The capacity of the existing interconnection between Morocco and Spain is 1400 MW [14]. A new interconnection submarine with Spain of $700 \mathrm{MW}$ guarantees security and reliability of supply, thus contributing to the stability of both systems as a whole [15].

\subsubsection{Morocco-Algeria interconnection}

The first $225 \mathrm{KV}$ electrical interconnection between Morocco and Algeria was commissioned in 1988 with a capacity of 200 MW [16]. The installation of a second line, then a third, commissioned in 2009. The capacity of the plant is increased to $300 \mathrm{MW}$, with new double lines to $400 \mathrm{KV}$ between Sid Ali Boussidi (Algeria) and Bourdim (Morocco) [17].

\subsubsection{Morocco-Portugal interconnection}

The study for the project begins in 2016 to build an interconnection with a capacity of 1000 MW [18], this first interconnection, which will help the two countries to exchange electricity. The project will also inject electricity from renewable sources.

Recommendations and solutions to remove some barriers to the deployment of smart ... (Rachid Habachi) 


\subsubsection{Morocco-Mauritania interconnection}

This interconnection has objectives: To strengthen the development of renewable energies in the region by connecting the Western European and African electricity grid through the Morocco-Spain interconnection [19].

\subsection{Renewable energy potential in Morocco}

Morocco is ready to lead the MENA region (Middle East and North Africa) in the renewable energy sector. The limitation of conventional hydrocarbon resources, the strong import of energy from other countries to meet its energy demand, the Moroccan government has historically resorted to the import of fossil fuels and the rapid increase in demand for electricity have boosted the development of renewable energies in Morocco and proved to be stable. Investment objective in the energy sector [20]. To solve its energy problems, the Kingdom of Morocco is turning to the development of renewable energies, including wind, solar and hydro.

Morocco has the most ambitious targets for renewable energy in the MENA region, pledging to increase renewable energy production to $42 \%$ of its electricity production by 2020 and $52 \%$ by 2030 .

\subsubsection{State and prospects of wind energy}

In Morocco, there are some of the world's largest wind sources, with 3,500 km of coastline and wind speeds of up to $11.5 \mathrm{~m} / \mathrm{s}$ at a height of $80 \mathrm{~m}$. The total wind potential in Morocco is estimated at around 25 GW [21]. Morocco's total installed wind capacity at the end of 2016 was 803 MW [22].

\subsubsection{State and prospects of solar energy}

Similar to wind energy, solar energy depends on weather conditions. A variation of the weather, such as clouds and energy, is available only during sunshine hours. As a result, solar energy production varies by season, location, and time of day.

Many technologies are used to develop solar radiation, including solar thermal energy, concentrated solar power plants (CSP), solar chimneys or solar power plants, as well as photovoltaic systems. One of the advantages of photovoltaic technology over other technologies is the ability to integrate a PV sensor into the building by transforming exterior walls, windows and roofs into a PV sensor.

Many technologies are used to develop solar radiation, including solar thermal energy, concentrated solar power plants (CSP), solar chimneys or solar power plants, as well as photovoltaic systems. One of the advantages of photovoltaic technology over other technologies is the ability to integrate a PV sensor into the building by transforming exterior walls, windows and roofs into a PV sensor.

CSP technologies refer to facilities that produce electrical energy using concentrated solar radiation. In general, CSP plants use large surface mirrors to focus sunlight on a relatively small aperture receiver. Due to its geographical location, Morocco is one of the most important solar potentials in the world, estimated at more than $5 \mathrm{kWh} / \mathrm{m} 2 /$ day (to increase production capacity, the Kingdom of Morocco has set itself a specific objective solar energy, concentrated solar energy (CSP) and photovoltaic (PV) by 14\% (2000 MW) by 2020 and $20 \%$ (4560 MW) by 2030 of production capacity from the country

Morocco's total installed solar energy capacity consisting solely of CSP technology at the end of 2016 [9] was $180 \mathrm{MW}$, ie $160 \mathrm{MW}$ for the Ouarzazate Noor I project currently in service and $20 \mathrm{MW}$ of solar thermal power plants and gas - AinBniMathar [23]. Similarly, for wind power, the Kingdom aims to increase the installed capacity of solar photovoltaic power and CSP production to at least 2,000 MW by 2020 and to 4,560 MW by 2030 [9]. The Moroccan Solar Energy Agency (MASEN) is responsible for many aspects of solar energy (CSP and PV) in the country and ONEE itself plans to create a number of medium-sized photovoltaic systems [24].

\subsubsection{Hydroelectricity}

The installation of hydropower generation capacity in Morocco started in the 1960s. This capacity has increased every year. Currently, Morocco has 26 traditional hydroelectric plants with a capacity of 1360 MW and 464 MW of pumped energy storage (PES) in an oven. Hydropower can be considered a traditional element of Moroccan power stations (the installed capacity in 2015 was $1,770 \mathrm{MW}$ ) and its potential is well exploited. ONEE is generally responsible for the construction of hydropower projects. To achieve its 2000 MW target by 2020, ONEE plans to build a new 350 MW PES at the Abdelmoumen site, bringing the capacity to $2120 \mathrm{MW}[23]$.

Int J Pow Elec \& Dri Syst, Vol. 10, No. 2, June 2019: $744-752$ 


\subsubsection{Biomass energy}

The vast Moroccan agricultural sector and the fact that a large part of the waste generated consists of organic components favor the production of electricity from biomass and biogas [25]. In Morocco, particularly in rural areas, there is a significant amount of forest residues and crops.

This helped the country to advance a promising renewable energy source of biomass energy. Biomass is an organic substance such as crops, wood and animal waste that can be used as a source of energy. Morocco's objectives are to strengthen the biomass zone, with a way to replace oil in the industrial sector. However, no national strategy is currently in place to exploit this potential, although some small businesses have already begun to make progress in this area [26].

\subsubsection{Geothermal energy}

Geothermal energy is energy available as energy included or supplied from the earth's crust [27]. In Morocco, there are several important areas in which geothermal energy could be used more for greenhouses, aquacultures, heat pumps, etc. The use of geothermal energy will help Morocco produce enough food for its domestic market as well as for its export. The current situation of geothermal energy in Morocco is estimated at 5.02 MWt (megawatt thermal) and $22 \mathrm{GWh} /$ year as annual use for swimming and swimming, other applications such as electricity generation [28] [29].

\section{OBSTACLES TO THE DEVELOPMENT AND IMPLEMENTATION OF SMART GRIDS IN MOROCCO}

\subsection{The existing barriers in the literature}

To meet the requirement to intelligently manage the intermittency of renewable energy sources in order to avoid future supply failures, which provide an excellent opportunity for the deployment of smart grid technologies, adoption must be considered a excellent opportunity [30].

According to the European Commission, the costs of achieving smart grids in Europe could reach tens of billions of euros. It includes the setting up of 30 million smart meters at a cost of 4 billion euros over 8 years. In the United States, the improvement of the network (particularly with respect to power cuts) would save $\$ 46$ to 117 billion between 2010 and 2023 .

However, the setting up of smart electrical networks raises technological, political and societal issues and therefore raises some issues [31].

- Huge amount of investment and lack of financial resources: Huge amount of investment is required to install smart grid. Investors are not interested to invest in smart grid installations until universal standards are adopted and return on investments is guaranteed

- Market uncertainty: Due to lack of revenue uncertainty and sufficient market base, private investment is discouraged.

- Lack of regulatory framework: Traditional regulatory system is needed to be modified to encourage utilities to invest in the smart grid installations.

- Low public awareness and engagement: The benefits of a smart grid can be achieved only if customers are fully aware of smart grid concept and they use all of its features

- Lack of innovativeness in the industry: Organizational attitudes towards innovation are not enthusiastic. They have fear of adopting newer technologies

- Lack of infrastructure: Additional infrastructure is required to deploy smart grid technologies

- Technology immaturity: Smart grid technologies are still emerging and standards are to be developed and maintained

- Lack of necessary technical skills and knowledge: There is a shortage of training and technical staff required for deploying and operating especially intra grid control applications

- Integration of the grid with large scale renewable generation: Integration of innovative technologies like renewable/sustainable energy technologies and distributed generation, into existing grids is a challenging task.

- Need of advanced bi-directional communication system: The bi-directional communication links may be harmed by natural disasters, man-made accidents and international attempts.

- Lack of open standards: Many proprietary standards used today need to be replaced by open standards worldwide

- Cyber security and data privacy: Smart grid communication technologies and consumer data are open to cyber-attack

Recommendations and solutions to remove some barriers to the deployment of smart ... (Rachid Habachi) 


\subsection{Barriers to the deployment of smart grids in Morocco}

The inclusion of renewable energies in the production of electricity, Morocco is indispensable for its socio-economic development. The Moroccan government and key leaders are issuing new regulations to deal with the country's energy transition. New projects are planned and production capacity will continue to increase to meet growing demand, but renewables are only a small part of the smart grid. The latter requires extensive monitoring and surveillance, information and communication technologies, advanced metering infrastructure, distributed generation, client-side systems and an EV charging infrastructure.

The first challenge lies in the levels of transmission and distribution; in fact, these losses reached a percentage of $14.7 \%$ in 2014 , so it is imperative to reduce them to secure the network [32]. The percentage has been rising since 2004, when it was as low as 5\% [32]. In order to reduce losses, an extensive surveillance network needs to be put in place. With regard to the transmission infrastructure, more lines are deployed at the level, the metering infrastructure is still based on conventional (electromagnetic) meters. It is clear that an MAI must be implemented. For example, in light of Law 58-15, the integration of low voltage REs will require a metering infrastructure that will allow utilities to bill customers accordingly and implement a particular pricing system. In addition, if Moroni plans to implement measures to minimize peaks, it will be important to involve customers, which can only be done with an AMI.

The introduction of energy management systems and dynamic pricing could significantly improve energy efficiency and optimize the use of locally generated renewable energy. The country will have to implement social awareness initiatives to promote the use of distributed generation. The importance of the SG must also be highlighted and the various demand response programs must be explained to the public in order to show the benefits that customers can derive from the installation of an MAI. Security is also a challenge in implementing an SG. The country needs to secure the most secure network for its customers so they can trust public services and share their private data.

\subsection{Solutions and recommendations for the development of smart grid in morocco}

Morocco is firmly committed to the large-scale development of renewable energy sources. Nevertheless, important challenges and obstacles still need to be resolved in order to unleash the full development potential of a sustainable electricity system. The following recommendations are intended to shed light on various aspects that should be improved to achieve an integrated and coherent development of renewable energy development in Morocco [33] [34]:

- Improve sectoral interaction within and within government institutions to work together for renewable energy by promoting transparency and collaboration while minimizing institutional fragmentation.

- Increase National R \& D (Research and Development) Capacity in Renewable Energy Deployment: R \& D is an important element in the long-term control of technologies, the development of know-how and the improvement of the performance of renewable energies. The development of sustainable renewable energy programs in Morocco requires a critical mass of $\mathrm{R} \& \mathrm{D}$ and a combination of the main operators (utilities, industries) and research centers. To increase the development of the renewable energy sector, four main dedicated state agencies have been created [34] [35]:

-The Research Institute for Solar and New Energies (IRESEN) was created in 2011 to support the national strategy and translate it into $\mathrm{R} \& \mathrm{D}$ projects and cooperate with international partners from France, Germany and from Spain.

-The Moroccan Solar Energy Agency (MASEN) has three main responsibilities: a) developing solar energy and other renewable energy projects, b) contributing to the development of national skills, and c) proposing regional and national plans for solar energy. And other ER technologies.

-The National Agency for Renewable Energy and Energy Efficiency (ADEREE) develops national, regional and sectoral plans for renewable energy and energy efficiency.

-Energy Investment Corporation (SIE): according to its own mission statement, the company facilitates and develops projects in the energy sector with the support of investor partners, developers and the private sector

- The decentralized production injection has a significant impact on the operation of the medium voltage network. This primarily concerns the distribution network manager, as he is responsible for managing a reasonable level of reliability, quality and security. The network manager is increasingly in need of observability via power grid tools.

- Increase the role of universities and researchers in international knowledge transfer to increase the development of renewable energy

Int J Pow Elec \& Dri Syst, Vol. 10, No. 2, June 2019: 744 - 752 


\section{CONCLUSION}

Morocco has an exceptional potential in Renewable Energy, particularly in solar and wind energy. The development of the Smart Grid in Morocco does not reach maturity as in Europe or North America. In this paper we have described the Moroccan network and studied the barriers to deployment of smart grids in morocco. We have finished by solutions and recommendations to development the smart grids in morocco

\section{ACKNOWLEDGEMENTS}

The authors are very much thankful to the unanimous reviewers of the paper and editors of the journal for their constructive and helpful comments that improved the quality of the paper.

\section{REFERENCES}

[1] Rachid Habachi et al. "Management and Control of Smart Grid Systems: Opportunities and Challenges in Morocco". International Journal of Mathematics and Computational Science ISSN: 2381-7011 (Print), ISSN, 2381702X, Vol. 3, No. 2, pp. 6-14, 2017.

[2] Minister of Energy of Mines, Water and Environment (MEMEE). "The Strategy of Renewable Energy For SelfConsumption In The Industry Sector". Casablanca, November 2014.

[3] International Energy Agency, Morocco 2014: Energy policies beyond IEA countries, Paris, 2014.

[4] C.He-Rui, P. Xu, "Study on Smart Grid System Based on System Dynamics", TELKOMNIKA Indonesian Journal of Electrical Engineering, Vol. 12, No. 12, pp. 7979-7986, December 2014

[5] Shahinzadeh H, Hasanalizadeh-Khosroshahi A. "Implementation of Smart Metering Systems: Challenges and Solutions". TELKOMNIKA Indonesian Journal of Electrical Engineering, 12(7), 2014.

[6] Ayla Hasanalizadeh-Khosroshahi et al "Security Technology by using Firewall for Smart Grid". Bulletin of Electrical Engineering and Informatics ISSN: 2302-9285, Vol. 5, No. 3, pp. 366 372, September 2016, DOI: 10.11591/eei.v5i3.615

[7] ONEE, OUR SPECIALTIES. http://www.oneecop22.ma, 2016.

[8] Gao J, "A survey of communication/networking in Smart Grids". Future Generation Computer Systems (Elsevier), pp. 391-404, 2012.

[9] National Office of Electricity, Annual Activity Reports of ONEE version; 2014. [online] Available: www.one.org.ma

[10] Gao J, "A survey of communication/networking in Smart Grids”. Future Generation Computer Systems (Elsevier), pp. 391-404, 2012.

[11] Official bulletin number 2650 of 09.08 .1963 Dahir $n{ }^{\circ}$ 1-63-226 (14 rebia I 1383) creating the National Office of Electricity.

[12] Official Bulletin No. 46-80-2 chaoual 1437 (7-7-2016) Law No. 48-15 on the regulation of the electricity sector and the creation of the National Electricity Regulatory Authority.

[13] MEMEE. Regional integration strategic choice of Morocco, "Strengthening and development of energy interconnection with neighboring coun-tries", Available http://www.mem.gov.ma/SitePages/CP2016/CP09Juin16.aspx, 2016.

[14] National Office of Electricity and Water (ONEE), http://www.one.org.ma/, 2015.

[15] RedEléctrica de España, 2ème interconnexion électrique Espagne-Maroc. www.ree.es

[16] B. Mohamed, B. Assa, \& B. Ilhem. "Electric network interconnection of Maghreb Arab countries". Proceedings of 10th international conference on environment and electrical engineering (EEEIC), Rome, Italy, 8-11, 4 pp, May 2011.

[17] T. Kousksou, P. Bruel, A. Jamil, T. El Rhafiki, \& Y. Zeraouli. "Energy storage: Applications and challenges. Solar Energy Materials and Solar Cells", 120, 59-80, 2014

[18] Feasibility Study on Morocco-Portugal Electric Interconnection Launched. https://www.moroccoworldnews.com, 2016.

[19] Presentation by Brahim Oumounah. "Intégration des énergies renouvelables dans les systèmes électriques nationaux". ONEE-COP22, http://www.oneecop22.ma, 2016.

[20] ONEE, OUR SPECIALTIES. http://www.oneecop22.ma, 2016.

[21] MENA-SELECT, "Country Fact Sheet Morocco Energy and Development at a glance 2016". Available from: https://germanwatch.org/en/download/15121.pdf.

[22] Moroccan Agency for Solar Energy (MASEN). http://www.masen.ma/ar/projets/, 2017.

[23] C. Richts. "The Moroccan solar plan. A comparative analysis of CSP and PV utilization until 2020". 2012.

[24] B. Mohamed, B. Assa, \& B. Ilhem. "Electric network interconnection of Maghreb Arab countries". Proceedings of 10th international conference on environment and electrical engineering (EEEIC), 4 pp, Rome, Italy, 8-11 May 2011

[25] Afilal ME, N. Belkhadir, Z. Merzak. "Biogas production from anaerobic digestion of manure waste: Moroccan case”. Global J Sci Front Res, 2013.

[26] Moroccan Agency for Renewable Energy Development and Energy Efficiency; http://www.aderee.ma/

[27] A. Rimi, Y. Zarhloule, AE. Barkaoui, Correiac Antonio, J. Carneiro, M. Verdoya, F. Lucazeau. "Towards a decarbonized energy system in northeastern Morocco: prospective geothermal resource". Renewable Sustainable Energy Rev, 16:220716, 2012. 
[28] JW. Lund, DH. Freeston, TL. Boyd. "Direct utilization of geothermal energy worldwide review". Proceedings world geothermalcongress, Bali, Indonesia; April 2010.

[29] T. Kousksou, A. Allouhi, M. Belattar, A. Jamil, T. El Rhafiki, A. Arid, \& Y. Zeraouli. "Renewable energy potential and national policy directions for sustainable development in Morocco". Renewable and Sustainable Energy Reviews, 47, 46-57, 2015.

[30] Brown MA, ZhouS. "Smart-gridpolicies: an international review". Wiley Interdiscip Rev: Energy Environ; 2(2): 121-39, 2013.

[31] S. Luthra, S. Kumar, R. Kharb, M. F. Ansari, and S. L. Shimmi, "Adoption of smart grid technologies: An analysis of interactions among barriers," Elsevier, vol. 33, no. Renewable and Sustainable Energy Reviews, pp. 554-565, 2014.

[32] World Bank Group, "The World Bank". IEA Statistics, 2014. [Online]. Available: http://data.worldbank.org/indicator/. [Retrieved April, 2018].

[33] "The Renewable Energy Sector in North Africa": Current Situation and Prospects, Subregional North Africa Office of the United Nations Economic Commission for Africa (UNECA), 2012.

[34] MENA-SELECT, "Country Fact Sheet Morocco Energy and Development at a glance 2016". Availablefrom: https://germanwatch.org/en/download/15121.pdf.

[35] K Choukri, A Naddami, S Hayani, "Renewable energy in emergent countries: lessons from energy transition in Morocco". Energy, Sustainability and Society, Springer, 2017.

Int J Pow Elec \& Dri Syst, Vol. 10, No. 2, June 2019: $744-752$ 